\title{
Article \\ Maternal Death Related to Sudden Unexpected Death in Epilepsy: A Nationwide Survey in Japan
}

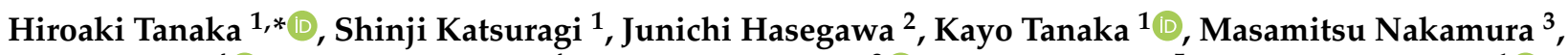

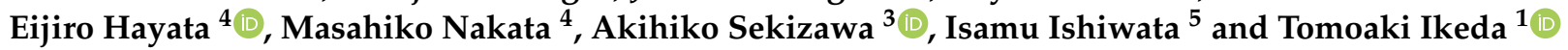 \\ 1 Department of Obstetrics and Gynecology, Mie University School of Medicine, 2-174 Edobashi, \\ Tsu 514-8507, Japan; skatsura@clin.medic.mie-u.ac.jp (S.K.); tagami.t.ky@gmail.com (K.T.); \\ t-ikeda@clin.medic.mie-u.ac.jp (T.I.) \\ 2 Department of Obstetrics and Gynecology, St. Marianna University School of Medicine, 2-16-1 Sugao, \\ Miyamae, Kawasaki 216-8511, Japan; hasejun@marianna-u.ac.jp \\ 3 Department of Obstetrics and Gynecology, Showa University School of Medicine, 1-5-8 Hatanodai, \\ Shinagawa, Tokyo 142-8666, Japan; nakamula-m@med.showa-u.ac.jp (M.N.); \\ sekizawa@med.showa-u.ac.jp (A.S.) \\ 4 Department of Obstetrics and Gynecology, Toho University Omori Medical Center, 6-11-1 Omorinishi, Ota, \\ Tokyo 143-8540, Japan; e_hayata@hotmail.com (E.H.); masahiko.nakata@med.toho-u.ac.jp (M.N.) \\ 5 Department of Obstetrics and Gynecology, Ishiwata Hospital, 1-4-21 Kamimito, Mito 310-0041, Japan; \\ mismtiis@mito.ne.jp \\ * Correspondence: h_tanaka@med.miyazaki-u.ac.jp; Tel.: +81-059-232-1111; Fax: +81-059-231-5202
}

\section{check for} updates

Citation: Tanaka, H.; Katsuragi, S.; Hasegawa, J.; Tanaka, K.;

Nakamura, M.; Hayata, E.;

Nakata, M.; Sekizawa, A.; Ishiwata, I.;

Ikeda, T. Maternal Death Related to

Sudden Unexpected Death in

Epilepsy: A Nationwide Survey in

Japan. Brain Sci. 2021, 11, 995.

https: / / doi.org/10.3390/

brainsci11080995

Academic Editor: Simona Lattanzi

Received: 29 June 2021

Accepted: 27 July 2021

Published: 28 July 2021

Publisher's Note: MDPI stays neutral with regard to jurisdictional claims in published maps and institutional affiliations.

Copyright: (c) 2021 by the authors. Licensee MDPI, Basel, Switzerland. This article is an open access article distributed under the terms and conditions of the Creative Commons Attribution (CC BY) license (https:/ / creativecommons.org/licenses/by/ $4.0 /)$.

\begin{abstract}
Sudden unexpected death in epilepsy (SUDEP) is defined as the sudden death of a patient with epilepsy in the absence of an anatomic or toxicologic cause. Whether pregnancy is a risk factor for SUDEP is unclear. Using data submitted to the Japan Association of Obstetricians and Gynecologists (JAOG), which has been collating information regarding all maternal deaths in Japan since 2000, this study evaluated maternal mortality data from 2010 to 2019 to evaluate the current circumstances of maternal death related to SUDEP in Japan. Six women died due to SUDEP during this period; the maternal mortality rate related to SUDEP was $0.066 / 100,000$ individuals. Two women each died during the second trimester, third trimester, and postpartum period. Four and two women were receiving monotherapy and no therapy with anti-epileptic drugs, respectively. The duration of epilepsy was $\leq 15$ years in three women, $>15$ years in one woman, and unknown in two women. This study furthers our understanding of the prevalence of maternal deaths due to SUDEP in Japan. Further studies are needed to confirm whether pregnancy is a risk factor for SUDEP.
\end{abstract}

Keywords: maternal death; pregnancy; sudden unexpected death in epilepsy; epilepsy

\section{Introduction}

Sudden unexpected death in epilepsy (SUDEP) is defined as the sudden death of a patient with epilepsy in the absence of an anatomic or toxicologic cause [1]. In recent years, SUDEP has received increasing attention because the incidence of sudden death in patients with epilepsy is approximately 20 times higher than that of the general population [2]. Several mechanisms for SUDEP have been suggested including hypoventilation due to an epileptic attack, arrhythmia, central neural dysfunction, and autonomic nervous system dysfunction [3-9]. Furthermore, high frequency of tonic-clonic convulsions, male sex, long duration of epilepsy, and multidrug therapy have been proposed as risk factors for SUDEP [10-21]. However, it is unclear whether pregnancy is a risk factor for SUDEP.

The prevalence of epilepsy is 8 in 1000, and it is estimated to affect over 1,000,000 patients in Japan [22]. Therefore, a substantial number of patients with epilepsy become pregnant. The aim of this study was to investigate the current circumstances of maternal death related to SUDEP in Japan. 


\section{Materials and Methods}

Information regarding all maternal deaths in Japan has been gathered by the Japan Association of Obstetricians and Gynecologists (JAOG) since 2010. The details of all maternal deaths in Japan are submitted to the JAOG, and the individual data is analyzed by the Maternal Death Exploratory Committee (Chairman: Ikeda, T.). This committee consists of 15 obstetricians, four anesthesiologists, two pathologists, an emergency physician, and various specialists who attend the review sessions each month and make annual recommendations aimed at reducing the maternal mortality rate. The present study was performed by this committee as part of a series of analyses on maternal deaths in Japan, using maternal mortality data from 2010 to 2019. We investigated the rate of maternal deaths related to epilepsy in Japan, and maternal death was defined as maternal death from pregnancy to 42 days postpartum.

The diagnosis of definite SUDEP was made when the following conditions were met: (1) a history of epilepsy (more than one epileptic attack within five years), (2) sudden death, (3) unexpected death (death in the absence of an apparent associated disease), and (4) unexplained death despite a thorough investigation of the causes of sudden death [1] A diagnosis of probable SUDEP was made when criteria of (1)-(3) but not (4) were met [1].

The following demographic and diagnosis-related data were collected for each patient, namely maternal background; age; parity; diagnosis of SUDEP; periods of death (trimester of pregnancy or postpartum); antiepileptic drug (AED) therapy including lamotrigine therapy; epilepsy attacks; annual frequency of generalized tonic-clonic seizure (GTCS) over the preceding three years and during pregnancy; presence of a bystander at the time of death, duration of epilepsy; and autopsy results.

This study was approved by the ethics committee of the National Cerebral and Cardiovascular Center of Japan under the title "Research on a model project regarding surveys and evaluations on maternal mortality in Japan" (receipt number N18-34).

\section{Results}

The total number of maternal deaths between January 2010 and December 2018 in Japan was 407. Maternal death related to epilepsy occurred in seven women: six due to SUDEP and one due to seizures. The combined number of all pregnancies resulting in live birth or fetal deaths in Japan during the study period was 9,039,897 pregnancies. The total number of maternal deaths related to SUDEP was 6/9,039,897 pregnancies. The maternal mortality rate related to SUDEP was $0.066 / 100,000$ pregnancies. The mortality related to epilepsy for trienniums between 2010 and 2018 is shown in Table 1.

Table 1. The mortality related to epilepsy for the trienniums between and including 2010-2018 in Japan.

\begin{tabular}{ccccc}
\hline & Numbers of Pregnancies & $\begin{array}{c}\text { Number of } \\
\text { Maternal Deaths }\end{array}$ & $\begin{array}{c}\text { Number of Deaths } \\
\text { Related to Epilepsy }\end{array}$ & $\begin{array}{c}\text { Maternal Death Rate } \\
\text { Related to Epilepsy }\end{array}$ \\
\hline $2010-2012$ & $3,159,341$ & 146 & 0 & 0 \\
$2013-2015$ & $3,039,032$ & 133 & 5 & 0.16 \\
$2016-2018$ & $2,841,524$ & 128 & 2 & 0.07 \\
\hline
\end{tabular}

The characteristics of maternal death in the six cases related to SUDEP are shown in Table 2. Four and two women met the criteria for probable and definite SUDEP, respectively. The periods of death were the second trimester in two women, third trimester in two women, and postpartum in two women. Four and two women were receiving AED monotherapy and no AED therapy, respectively. One patient was taking lamotrigine. The duration of epilepsy was $\leq 15$ years in three women, $>15$ years in one woman, and unknown in two women. GTCS frequency per year (more than three times per year) was around 1 year of pregnancy. 
Table 2. The characteristics of maternal death cases related to SUDEP.

\begin{tabular}{|c|c|c|c|c|c|c|c|c|c|}
\hline No. & $\begin{array}{l}\text { Maternal } \\
\text { Age }\end{array}$ & Primipara & Diagnosis & $\begin{array}{l}\text { Period of } \\
\text { Death }\end{array}$ & $\begin{array}{c}\text { AED } \\
\text { Therapy }\end{array}$ & Autopsy & $\begin{array}{l}\text { Lamotrigine } \\
\text { Therapy }\end{array}$ & $\begin{array}{l}\text { Duration of } \\
\text { Epilepsy }\end{array}$ & $\begin{array}{c}\text { GTCS } \\
\text { Frequency Per } \\
\text { Year }\end{array}$ \\
\hline 1 & $40 \mathrm{~s}$ & Yes & $\begin{array}{l}\text { Probable } \\
\text { SUDEP }\end{array}$ & Postpartum & $\begin{array}{l}\text { No AED } \\
\text { therapy }\end{array}$ & No & No & Unknown & No \\
\hline 2 & $20 \mathrm{~s}$ & Yes & $\begin{array}{l}\text { Definite } \\
\text { SUDEP }\end{array}$ & Postpartum & Monotherapy & Yes & No & $\leq 15$ years & No \\
\hline 3 & $30 \mathrm{~s}$ & No & $\begin{array}{l}\text { Probable } \\
\text { SUDEP }\end{array}$ & $\begin{array}{l}\text { Second } \\
\text { trimester }\end{array}$ & Monotherapy & No & No & Unknown & No \\
\hline 4 & $40 \mathrm{~s}$ & No & $\begin{array}{l}\text { Probable } \\
\text { SUDEP }\end{array}$ & $\begin{array}{l}\text { Second } \\
\text { trimester }\end{array}$ & $\begin{array}{l}\text { No AED } \\
\text { therapy }\end{array}$ & No & No & $\leq 15$ years & $3<$ \\
\hline 5 & $30 \mathrm{~s}$ & Yes & $\begin{array}{l}\text { Definite } \\
\text { SUDEP }\end{array}$ & $\begin{array}{l}\text { Third } \\
\text { trimester }\end{array}$ & Monotherapy & Yes & Yes & $>15$ years & No \\
\hline 6 & $20 \mathrm{~s}$ & Yes & $\begin{array}{l}\text { Probable } \\
\text { SUDEP }\end{array}$ & $\begin{array}{l}\text { Third } \\
\text { trimester }\end{array}$ & Monotherapy & No & No & $\leq 15$ years & No \\
\hline
\end{tabular}

SUDEP, sudden unexpected death in epilepsy; AED, anti-epileptic drug; GTCS, generalized tonic-clonic seizure.

\section{Discussion}

This study analyzed maternal mortality associated with epilepsy in Japan. We clarified the total number of deaths from epilepsy and SUDEP during pregnancy in Japan, and demonstrated that most epilepsy-related maternal deaths were SUDEP rather than convulsions.

According to the Center for Maternal and Child Enquiries in the United Kingdom (UK), the maternal mortality rate for epilepsy from 1991 to 2008, calculated on a 3-year basis, was 0.39-0.86; SUDEP accounted for about half of all epilepsy-related maternal deaths. The rates of epilepsy-related maternal mortality in Japan are much lower than those in the UK, and unlike the UK, most epilepsy-related maternal deaths in Japan were SUDEP. These differences in epilepsy-related maternal mortality between Japan and other countries need to be clarified in future studies; one possible explanation may be the lower pregnancy rates among women with severe or uncontrolled epilepsy in Japan.

Understanding the mechanism of SUDEP is the key to prevention. Previous studies have demonstrated that AED multitherapy, chronic epilepsy, lamotrigine therapy, an epileptic heart (heart and coronary vasculature damaged by chronic epilepsy as a result of re-peated surges in catecholamines and hypoxemia, leading to electrical and mechanical dysfunction), and frequent GTCS are risk factors for SUDEP [23,24]. A recently published article has shown that cardiac iron accumulation can trigger ferroptosis and be the cause of SUDEP [25]. However, we did not find a clear association between these factors and SUDEP in this study. Therefore, it is plausible that there are currently unidentified risk factors for SUDEP, which need to be identified through future studies in order to formulate effective preventive strategies.

The general incidence of SUDEP in epilepsy patients has been reported to be $0.1-1 / 1000$ per year [25]. In Japan, there is no national registry of pregnant women with epilepsy, and the rates of SUDEP among all pregnant women is unknown and it is important to clarify the total number of SUDEP cases during pregnancy in Japan. Therefore, it remains to be verified whether pregnancy is a risk factor for SUDEP, especially considering the fact that many women with well-controlled epilepsy can have healthy pregnancies and previous studies have established that SUDEP is more likely to occur when chronic control is poor [26]. However, as shown in this study, patients with well-controlled epilepsy, including those with relatively short durations of epilepsy, can also develop SUDEP during pregnancy, and the mechanism and triggers have not been clarified. This study has some limitations worth noting including its retrospective design. Future prospective studies are warranted to confirm the association of SUDEP with pregnancy in Japan.

\section{Conclusions}

We clarified the prevalence of maternal deaths related to epilepsy in Japan and found that most maternal deaths associated with epilepsy were SUDEP. Notably, we found 
that women without risk factors for SUDEP developed SUDEP during pregnancy. This highlights the need for further studies to clarify the pathomechanism of SUDEP to develop preventative strategies.

Author Contributions: Conceptualization: H.T., S.K., J.H. and K.T.; Methodology: H.T. and M.N. (Masamitsu Nakamura); Validation: H.T. and E.H.; Formal analysis: H.T. and M.N. (Masahiko Nakata); Investigation: H.T.; Data curation: H.T.; Writing: H.T.; Supervision: A.S., I.I. and T.I. All authors have read and agreed to the published version of the manuscript.

Funding: This study was supported in part by a Health and Labor Sciences Research Grant (Grant Number H30-healthcare-general-014).

Institutional Review Board Statement: This study was approved by the ethics board of National Cerebral and Cardiovascular Center, Osaka, Japan (receipt number N18-34).

Informed Consent Statement: Informed consent was obtained from all subjects involved in the study.

Data Availability Statement: The data presented in this study are available on request from the corresponding author.

Acknowledgments: The authors thank all the physicians of the hospital facilities who reported the maternal deaths, and the academic committee members of the Japan Council for Implementation of Maternal Emergency Life-Saving System (J-CIMELS). This work was supported by the Japan Association of Obstetricians and Gynecologists (JAOG).

Conflicts of Interest: The authors declare no conflict of interest.

\section{References}

1. Nashef, L. Sudden Unexpected Death in Epilepsy: Terminology and Definitions. Epilepsia 1997, 38, S6-S8. [CrossRef] [PubMed]

2. Ficker, D.M.; So, E.L.; Shen, W.K.; Annegers, J.F.; O’Brien, P.C.; Cascino, G.D.; Belau, P.G. Population-Based Study of the Incidence of Sudden Unexplained Death in Epilepsy. Neurology 1998, 51, 1270-1274. [CrossRef]

3. Johnston, S.C.; Horn, J.K.; Valente, J.; Simon, R.P. The Role of Hypoventilation in a Sheep Model of Epileptic Sudden Death. Ann. Neurol. 1995, 37, 531-537. [CrossRef] [PubMed]

4. Johnston, S.C.; Darragh, T.M.; Simon, R.P. Postictal Pulmonary Edema Requires Pulmonary Vascular Pressure Increases. Epilepsia 1996, 37, 428-432. [CrossRef]

5. Johnston, S.C.; Siedenberg, R.; Min, J.K.; Jerome, E.H.; Laxer, K.D. Central Apnea and Acute Cardiac Ischemia in a Sheep Model of Epileptic Sudden Death. Ann. Neurol. 1997, 42, 588-594. [CrossRef]

6. Venit, E.L.; Shepard, B.D.; Seyfried, T.N. Oxygenation Prevents Sudden Death in Seizure-Prone Mice. Epilepsia 2004, 45, 993-996. [CrossRef] [PubMed]

7. Nashef, L.; Walker, F.; Allen, P.; Sander, J.W.; Shorvon, S.D.; Fish, D.R. Apnoea and Bradycardia During Epileptic Seizures: Relation to Sudden Death in Epilepsy. J. Neurol. Neurosurg. Psychiatry 1996, 60, 297-300. [CrossRef]

8. Bateman, L.M.; Li, C.S.; Seyal, M. Ictal Hypoxemia in Localization-Related Epilepsy: Analysis of Incidence, Severity and Risk Factors. Brain 2008, 131, 3239-3245. [CrossRef]

9. Seyal, M.; Bateman, L.M. Ictal Apnea Linked to Contralateral Spread of Temporal Lobe Seizures: Intracranial EEG Recordings in Refractory Temporal Lobe Epilepsy. Epilepsia 2009, 50, 2557-2562. [CrossRef]

10. Jick, S.S.; Cole, T.B.; Mesher, R.A.; Tennis, P.; Jick, H. Sudden Unexpected Death in Young Persons with Primary Epilepsy. Pharmacoepidemiol. Drug Saf. 1992, 1, 59-64. [CrossRef]

11. Opeskin, K.; Berkovic, S.F. Risk Factors for Sudden Unexpected Death in Epilepsy: A Controlled Prospective Study Based on Coroners Cases. Seizure 2003, 12, 456-464. [CrossRef]

12. Nilsson, L.; Farahmand, B.Y.; Persson, P.G.; Thiblin, I.; Tomson, T. Risk Factors for Sudden Unexpected Death in Epilepsy: A Case-Control Study. Lancet 1999, 353, 888-893. [CrossRef]

13. Walczak, T.S.; Leppik, I.E.; D’Amelio, M.; Rarick, J.; So, E.; Ahman, P.; Ruggles, K.; Cascino, G.D.; Annegers, J.F.; Hauser, W.A. Incidence and Risk Factors in Sudden Unexpected Death in Epilepsy: A Prospective Cohort Study. Neurology 2001, 56, 519-525. [CrossRef]

14. Leestma, J.E.; Annegers, J.F.; Brodie, M.J.; Brown, S.; Schraeder, P.; Siscovick, D.; Wannamaker, B.B.; Tennis, P.S.; Cierpial, M.A.; Earl, N.L. Sudden Unexplained Death in Epilepsy: Observations from a Large Clinical Development Program. Epilepsia 1997, 38, 47-55. [CrossRef] [PubMed]

15. Langan, Y.; Nashef, L.; Sander, J.W. Case-Control Study of SUDEP. Neurology 2005, 64, 1131-1133. [CrossRef] [PubMed]

16. Hitiris, N.; Suratman, S.; Kelly, K.; Stephen, L.J.; Sills, G.J.; Brodie, M.J. Sudden Unexpected Death in Epilepsy: A Search for Risk Factors. Epilepsy Behav. 2007, 10, 138-141. [CrossRef]

17. Birnbach, C.D.; Wilensky, A.J.; Dodrill, C.B. Predictors of Early Mortality and Sudden Death in Epilepsy: A Multidisciplinary Approach. J. Epilepsy 1991, 4, 11-17. [CrossRef] 
18. George, J.R.; Davis, G.G. Comparison of Anti-Epileptic Drug Levels in Different Cases of Sudden Death. J. Forensic Sci. 1998, 43, 598-603. [CrossRef]

19. Schnabel, R.; Beblo, M.; May, T.W. Is Geomagnetic Activity a Risk Factor for Sudden Unexplained Death in Epilepsies? Neurology 2000, 54, 903-908. [CrossRef] [PubMed]

20. Opeskin, K.; Harvey, A.S.; Cordner, S.M.; Berkovic, S.F. Sudden Unexpected Death in Epilepsy in Victoria. J. Clin. Neurosci. 2000, 7, 34-37. [CrossRef]

21. Shields, L.B.; Hunsaker, D.M.; Hunsaker, J.C., 3rd; Parker, J.C., Jr. Sudden Unexpected Death in Epilepsy: Neuropathologic findings. Am. J. Forensic Med. Pathol. 2002, 23, 307-314. [CrossRef]

22. Japanese Society of Neurology. Epilepsy Therapy. In Guideline 2010; Igakusyoin: Tokyo, Japan, 2010.

23. Shorvon, S.; Tomson, T. Sudden Unexpected Death in Epilepsy. Lancet 2011, 378, 2028-2038. [CrossRef]

24. Sveinsson, O.; Andersson, T.; Mattsson, P.; Carlsson, S.; Tomson, T. Clinical Risk Factors in SUDEP: A Nationwide PopulationBased Case-Control Study. Neurology 2020, 94, e419-e429. [CrossRef] [PubMed]

25. Akyuz, E.; Doganyigit, Z.; Eroglu, E.; Moscovicz, F.; Merelli, A.; Lazarowski, A.; Auzmendi, J. Myocardial Iron Overload in an Experimental Model of Sudden Unexpected Death in Epilepsy. Front. Neurol. 2021, 11, 609236. [CrossRef]

26. Tomson, T.; Nashef, L.; Ryvlin, P. Sudden Unexpected Death in Epilepsy: Current Knowledge and Future Directions. Lancet Neurol. 2008, 7, 1021-1031. [CrossRef] 